\title{
Yield and photochemical activity of selected rice cultivars from Eastern India under medium depth stagnant flooding
}

\author{
D. PANDA ${ }^{*, * *+,}$, A. RAY ${ }^{*}$, and R.K. SARKAR* \\ Division of Crop Physiology and Biochemistry, ICAR-National Rice Research Institute, 753006 Cuttack, India* \\ Department of Biodiversity and Conservation of Natural Resources, Central University of Orissa, 764021 Koraput, \\ Odisha, India ${ }^{* *}$
}

\begin{abstract}
Stagnant flooding (SF) is a serious threat for rice production in rainfed lowland areas of Southeast Asian countries. To overview the SF effect, photosynthetic performances and productivity were studied with three landraces (Ravana, Kamini, and Rashpanjor) and four high-yielding cultivars (Savitri, Savitri-Sub1, Gayatri, and Varshadhan) of rice under medium depth $(40-50 \mathrm{~cm})$ of water level. Stagnant flooding significantly increased the stem elongation and decreased yield and yield attributing parameters. The chlorophyll $a$ fluorescence rises from O- to P-step with distinct J- and I-step were noticed in all the cultivars up to $75 \mathrm{~d}$ of SF. Prolonged flooding ( $>2$ months) perturbed both donor and acceptor side of PSII. Vitality indices $\left(\mathrm{PI}_{\mathrm{ABS}}\right.$ and $\mathrm{PI}_{\mathrm{TOT}}$ ) decreased greatly under prolonged SF. Analysis of O-J-I-P transients suggests that the information is useful for agricultural planning with the purpose to enhance rice yield under lowland medium depth SF.
\end{abstract}

Additional key words: JIP-test; Oryza sativa; performance index; submergence; yield attributes.

\section{Introduction}

Rice yields in lowland areas are regularly affected by flooding during monsoon in many Southeast Asian countries (Goswami et al. 2017). Globally, rainfed lowland and deep-water rice account for about one third of the total rice-growing area, which is about 50 Mha (Bailey-Serres and Voesenek 2008). Broadly, four major kinds of rice ecology are found: medium deep (25-50 cm water depth), deep water ( $>50-100 \mathrm{~cm}$ water depth), very deep $(>100 \mathrm{~cm}$ water depth), and tidal wetland where water accumulates and stagnates for 1-4 months because of impeded drainage. Here, average rice productivity varies from 0.5 to $1.5 \mathrm{t}$ per ha depending on the depth of water stagnation (Sarkar et al. 2006, Vergara et al. 2014). Analysis of flooding pattern in rainfed lowland of Southeast Asia reveals that about 20 million ha comes under medium-deep water ecology based on water stagnation (Sarkar et al. 2006, Vergara et al. 2014). Most of the recent research has been focusing on developing varieties tolerant to complete submergence through transfer of the Submergence-1 (SUB1) gene into popular varieties (Xu et al. 2006, Sarkar et al. 2009, Bailey-Serres and Colmer 2014, Bin Rahman and Zhang 2016). Socially disadvantaged people from Asia to Africa who reside in the flood-prone area have got advantage of cultivation of submergence-tolerant rice (Sakagami and Kawano 2011, Dar et al. 2013). Though water stagnation and submergence are two most predominant stresses in flood-prone areas, yet work on stagnant flooding is limited unlike submergence tolerance. Depending on the depth of water stagnation, plant elongates to avoid complete submergence (Cattling 1992). To survive under very deep-water conditions $(>1.0 \mathrm{~m}$ depth), plant elongation occurs with rising floodwater. Overexpression of two genes, such as SNORKEL 1 (SK1) and SNORKEL 2 (SK2), allows rice to outgrow the rising floodwaters (Hattori et al. 2009) and thus, plants escape complete inundation. However, under medium depth

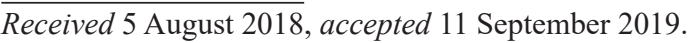

${ }^{+}$Corresponding author; phone: 91-6852-251288, fax: 91-6852-251244, e-mail: dpanda80@gmail.com

Abbreviations: ABS - absorption; $\mathrm{CS}$ - cross section; $\mathrm{ET}_{0}$ - electron transport by active PSII reaction centres leading to $\mathrm{Q}_{\mathrm{A}}$ reduction; $\mathrm{F}_{0}$ - minimal fluorescence intensity; $\mathrm{F}_{\mathrm{I}}$ - fluorescence intensity at $30 \mathrm{~ms} ; \mathrm{F}_{\mathrm{J}}$ - fluorescence intensity at $2 \mathrm{~ms} ; \mathrm{F}_{\mathrm{K}}$-fluorescence intensity at $300 \mu \mathrm{s}$; FLT - flowering time; $\mathrm{F}_{\mathrm{m}}$ - maximal fluorescence intensity; HI - harvest index; LSD - least significance difference; OEC - oxygen-evolving complex; $\mathrm{PI}_{\mathrm{ABS}}$ - performance index on absorption basis; $\mathrm{PI}_{\mathrm{TOT}}$ - total performance index on absorption basis; $\mathrm{PQ}$ - plastoquinone; $\mathrm{Q}_{\mathrm{A}}$ - primary quinone electron acceptors of PSII; $\mathrm{Q}_{\mathrm{B}}$ - secondary quinone electron acceptors of PSII; RC - reaction centre; SF - stagnant flooding; SK - SNORKEL gene; SUB1 - submergence tolerance gene; $\mathrm{TR}_{0}$ - flux of exciton trapping by active PSII reaction centres leading to $\mathrm{Q}_{\mathrm{A}}$ reduction; $\mathrm{V}_{\mathrm{K}}$ - relative variable fluorescence at the K-step (at $300 \mu \mathrm{s}$ ); $\Phi_{\mathrm{E} 0}$ - quantum yield of electron transport flux from $\mathrm{Q}_{\mathrm{A}}{ }^{-}$to $\mathrm{PQ}$ pool of PSII on absorption basis; $\Phi_{\mathrm{P} 0}-$ maximum quantum yield of primary PSII photochemistry that leads to $\mathrm{Q}_{\mathrm{A}}$ reduction; $\Phi_{\mathrm{R} 0}$ - quantum yield of reduction in the end electron acceptors of PSI on absorption basis; $\Psi_{\mathrm{E} 0}$ - efficiency or probability with which a PSII trapped electron is transferred from $\mathrm{Q}_{\mathrm{A}}^{-}$to PQ pool; $\Psi_{\mathrm{R} 0}-$ efficiency or probability with which a PSII trapped electron is transferred to final electron acceptors of PSI.

Acknowledgements: The authors are grateful to the Director, National Rice Research Institute, Cuttack, Odisha, for providing necessary facilities for the work. ICAR - Emeritus Scientist Program (RKS) is highly acknowledged for providing financial support.
} 
( $\approx 50 \mathrm{~cm}$ water depth) conditions, such extensive elongation is not warranted (Kuanar et al. 2017, Singh et al. 2017). Extensive elongation leads to heavy yield penalty. In order to adapt to medium depth water stagnation in addition to slow elongation, numbers of morphological, anatomical, and physiological changes are necessary even in rice (Striker 2012, Kuanar et al. 2017).

Water stagnation deteriorates photosynthetic activity in many plants irrespective of the sensitivity to SF (Striker 2012). To stabilize production, protection of photosynthetic apparatus is necessary under stressful environment. Chlorophyll (Chl) $a$ fluorescence is a good technique to measure the vitality of photosynthetic system (Oukarroum et al. 2007, Panda and Sarkar 2013, Sarkar and Ray 2016, Kalaji et al. 2018). Chl a fluorescence provides detailed information about the structure and function of the photosynthetic apparatus based on PSI electron transport, PSII functionality, oxygen-evolving complex, and intersystem electron transport capacity (Batra et al. 2016, Wang et al. 2017, Kalaji et al. 2018). Reports are available showing that photosynthesis is greatly affected due to flash flooding (Panda et al. 2006, 2008); however, the effect of stagnant flooding to PSII activity is less understood so far. Detailed information about photosynthetic performance in rice exposed to stagnant flooding during different stages is not available.

Therefore, the objectives of this study were to investigate structural and functional alteration of PSII under medium depth $(\approx 50 \mathrm{~cm}$ water depth) of stagnant flooding in rice. Attempts had been made to identify highly sensitive Chl fluorescence parameters, which changed readily under stagnant flooding and could predict the yield stability or better yielding ability under such conditions. Such information is useful for agricultural planning for the purpose to enhance rice yield under lowland medium depth stagnation of water.

\section{Materials and methods}

Plant material and growth conditions: The experiment was conducted by taking seven rice cultivars: Ravana, Kamini, Rashpanjor, Savitri, Savitri-Sub1, Gayatri, and Varshadhan from Eastern India at National Rice Research Institute, Orissa, India $\left(20.5^{\circ} \mathrm{N}, 86.0^{\circ} \mathrm{E} ; 23.5 \mathrm{~m}\right.$ a.s.l. $)$. Three rice cultivars, Ravana, Kamini and Rashpanjor, are farmers' selected cultivars, whereas the rest of the cultivars are high-yielding types. The rice cultivars Savitri, Savitri-Sub1, Gayatri, and Varshadhan were released for commercial cultivation for rainfed lowland situation under varying levels of water stagnation or flash flooding conditions. Savitri-Sub1 is tolerant to complete submergence and others are submergence susceptible.

The experiment was conducted during the wet season (June to December) of 2015-2016. Three healthy and uniform 21-d old seedlings were transplanted to an earthen pot $(30 \mathrm{~cm}$ height and $60 \mathrm{~cm}$ diameter) containing $10 \mathrm{~kg}$ of farm soil (sandy clay loam alluvial soil, $\mathrm{pH}$ 6.8) and farmyard manure in a 3:1 ratio. Chemical fertilizer at the rate of $1.5 \mathrm{~g} \mathrm{P}_{2} \mathrm{O}_{5}$ as single superphosphate and $0.80 \mathrm{~g}$ $\mathrm{K}_{2} \mathrm{O}$ as muriate of potash was added in each pot during the preparation of pot as basal. Each pot was considered as one replication. Urea was applied thrice at the rate of $1 \mathrm{~g}$ per pot after 7, 27, and $47 \mathrm{~d}$ of planting. The pots were placed in a concrete water tanks under a water depth of $50 \mathrm{~cm}$ (30 $\mathrm{cm}$ pot height and $20 \mathrm{~cm}$ absolute water depth) as a stagnant flooding plot. Thereafter, water level was maintained $20 \mathrm{~cm}$ above the pot up to harvesting stage. A control set was also maintained under normal water depth $(0-5.0 \mathrm{~cm})$ from transplanting to harvesting. Total rainfall, average maximum and minimum temperature, relative humidity, and sunshine hours were $1130 \mathrm{~mm}, 30.7$ and $24.6^{\circ} \mathrm{C}, 48-92 \%$, and $4.2-8.1 \mathrm{~h}$, respectively. The rice cultivars used in this investigation are photoperiod sensitive. Sowing of seeds was done in the $3^{\text {rd }}$ week of June. The flowering date of Varshadhan was $1^{\text {st }}$ week of November, whereas flowering dates of the rest of the cultivars were in $4^{\text {th }}$ week of October. Flowering date was 2-3 d delayed under stagnant flooding compared with control in all the cultivars except Varshadhan. In cv. Varshadhan, flowering date was 6-7 d delayed under SF compared with control. The experiment was conducted in a randomized complete block design with three replications. Different physiological measurements were carried out at $15,30,45,60$, and $75 \mathrm{~d}$ after transplanting and at flowering time (FLT) in control and stagnant flooding conditions.

Plant height and yield parameters: Plant height, yield, and yield-attributing parameters were recorded at harvest. Harvest index was determined as (grain yield)/(grain yield + straw). Data on panicle mass, straw mass, grain mass, and panicle number were presented as recently described in our laboratory by Ray et al. (2017).

Chl $\boldsymbol{a}$ fluorescence was measured on 20-min dark-adapted leaf (second leaf from the top) using a plant efficiency analyzer, Handy PEA (Hansatech Instruments, Norfolk, UK). Data were recorded from $0.01 \mathrm{~ms}$ up to $1 \mathrm{~s}$. Data acquisition up to first $0.30 \mathrm{~ms}$ were in every $0.01-\mathrm{ms}$ intervals, then every $0.10 \mathrm{~ms}$ up to $3.0 \mathrm{~ms}$, every $1 \mathrm{~ms}$ up to $30 \mathrm{~ms}$, every $10 \mathrm{~ms}$ up to $300 \mathrm{~ms}$, and after that $100 \mathrm{~ms}$. During the 1-s time period, 118 data point were obtained. The maximal intensity of the light source, providing an irradiance by saturating pulse of 3,000 $\mu$ mol(photon) $\mathrm{m}^{-2} \mathrm{~s}^{-1}$, was used. In each replication under a specific treatment, five individual leaves were used to measure Chl $a$ fluorescence transients. Average data of three replications were used to make the fluorescence transients curve. From the fast O-J-I-P transients, several bioenergetic parameters were derived using the formulae of BIOLYZER software (Bioenergetic Laboratory, University of Geneva). The empirical formula and physiological importance of these Chl $a$ fluorescence parameters are described following Stirbet et al. (2018). (1) Parameters related to overall PSII function: $\mathrm{V}_{\mathrm{K}}=\left(\mathrm{F}_{\mathrm{K}}-\mathrm{F}_{0}\right) /\left(\mathrm{F}_{\mathrm{m}}-\mathrm{F}_{0}\right)$, relative variable fluorescence at the K-step (at $300 \mu \mathrm{s}) ; \Phi_{\mathrm{P} 0}=\mathrm{TR}_{0} / \mathrm{ABS}=$ $\mathrm{F}_{\mathrm{v}} / \mathrm{F}_{\mathrm{m}}$, maximum quantum yield of primary PSII photochemistry that leads to $\mathrm{Q}_{\mathrm{A}}$ reduction. (2) Parameters related to the PSII acceptor side: $\mathrm{V}_{\mathrm{J}}=\left(\mathrm{F}_{\mathrm{J}}-\mathrm{F}_{0}\right) /\left(\mathrm{F}_{\mathrm{m}}-\mathrm{F}_{0}\right)$, relative variable fluorescence at the J-step (at $2 \mathrm{~ms}$ ); $\Psi_{\mathrm{E} 0}=$ $\mathrm{ET}_{0} / \mathrm{TR}_{0}=1-\mathrm{V}_{\mathrm{J}}$, efficiency or probability with which a 
PSII trapped electron is transferred from $\mathrm{Q}_{\mathrm{A}}{ }^{-}$to $\mathrm{PQ}$ pool; $\Phi_{\mathrm{E} 0}=\mathrm{ET}_{0} / \mathrm{ABS}=\Psi_{\mathrm{E} 0} \times \Phi_{\mathrm{P} 0}$, quantum yield of electron transport flux from $\mathrm{Q}_{\mathrm{A}}^{-}$to $\mathrm{PQ}$ pool of PSII on absorption basis. (3) Parameters related to overall function of PSI: $\mathrm{V}_{\mathrm{I}}=\left(\mathrm{F}_{\mathrm{I}}-\mathrm{F}_{0}\right) /\left(\mathrm{F}_{\mathrm{m}}-\mathrm{F}_{0}\right)$, relative variable fluorescence at the I-step (at $30 \mathrm{~ms}$ ); $\Psi_{\mathrm{R} 0}=\mathrm{RE}_{0} / \mathrm{TR}_{0}=1-\mathrm{V}_{\mathrm{I}}$, efficiency or probability with which a PSII trapped electron is transferred to final electron acceptors of PSI; $\Phi_{\mathrm{R} 0}=\mathrm{RE} / \mathrm{ABS}=$ $\Psi_{\mathrm{R} 0} \times \Phi_{\mathrm{P} 0}$, quantum yield of reduction in the end electron acceptors of PSI on absorption basis. (4) Vitality indexes: $\mathrm{PI}_{\mathrm{ABS}}=(\mathrm{RC} / \mathrm{ABS}) \times\left[\Phi_{\mathrm{P} 0} /\left(1-\Phi_{\mathrm{P} 0}\right)\right] \times\left[\Psi_{\mathrm{E} 0} /\left(1-\Psi_{\mathrm{E} 0}\right)\right]$, performance index on absorption basis, reflects function of electron transport to the $\mathrm{PQ}$ pool; $\mathrm{PI}_{\mathrm{TOT}}=\mathrm{PI}_{\mathrm{ABS}} \times$ $\left[\delta_{\mathrm{R} 0} /\left(1-\delta_{\mathrm{R} 0}\right)\right]$, total performance index on absorption basis, reflects function of all electron transport in the thylakoid membrane.

Calculation of L- and K-band: To envisage the L- and $\mathrm{K}$-band between $\mathrm{O}$ - and J-step, Chl $a$ fluorescence transient of each cultivar was double normalized between $\mathrm{F}_{0}$ $(0.05 \mathrm{~ms})$ and $\mathrm{F}_{\mathrm{K}}(0.30 \mathrm{~ms})$ (Strasser et al. 2004, Oukarroum et al. 2007) and $F_{0}$ and $F_{J}$ (Jiang et al. 2006), respectively. The data of control were subtracted from the data of the treated leaves. For clear images the subtracted data were multiplied by 10 and graphs were prepared.

Statistical analysis: Differences between various parameters were compared by analysis of variance (ANOVA) using CROPSTAT (International Rice Research Institute, Philippines). Mean values were compared by the least significant difference (LSD, $P<0.05$ ), when the $F$-test was significant. The standard deviations (SD) and correlation analysis were conducted by Microsoft Excel 2007. Correlation study was done taking Chl $a$ fluorescence parameters of flowering stage with yield and yield attributes.

\section{Results}

Effect of stagnant flooding on plant height and yield attributes: The plant height of all cultivars measured at maturity increased considerably under SF compared with the control plants, except for cv. Sabitri-Sub1, which did not show any significant difference (Fig. 1). Plant height was remarkably higher in cvs. Ravana, Rashponjor, and Varshadhan compared to Sabitri and Gayatri both under control and SF conditions.

Yield and yield attributes, such as grain yield, panicle number, panicle mass, fertile spikelet, and harvest index, in different cultivars under control and SF are presented in Table 1. Significant reduction of the yield was noticed under SF compared with control. Varietal differences of grain yield were also significant. The reduction of grain yield under SF ranged from $28-80 \%$ among the cultivars. Maximum reduction of grain yield was observed in cv. Kamini. A few cultivars, such as Ravana, Rashpanjor, and Varshadhan, produced significantly higher grain yield than that of flash flood-tolerant cv. Sabitri-Sub1 under SF. Similarly, significant reduction of panicle number and panicle mass were observed among the cultivars under

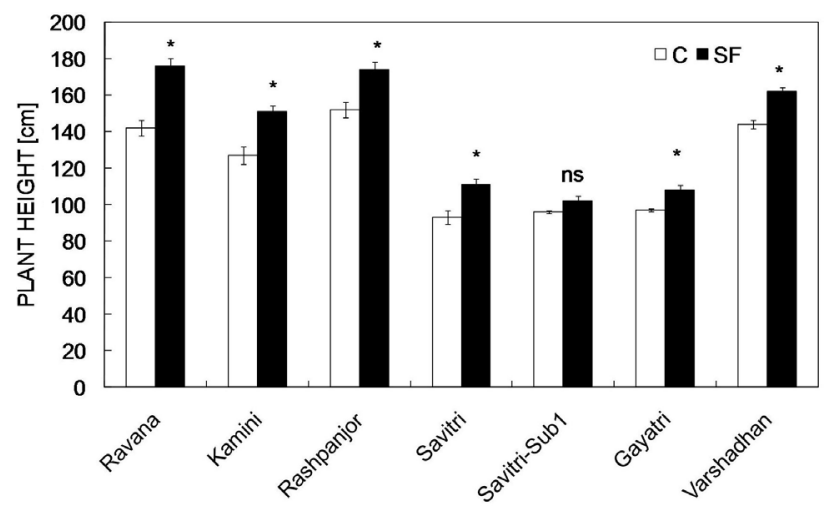

Fig. 1. Changes of plant height in different rice cultivars under control (C) and stagnant flooding (SF). Data are the means $\pm \mathrm{SD}$, $n=3{ }^{*}$ - significance at $P<0.05, \mathrm{~ns}-$ nonsignificant.

SF compared with respective control. The reduction of panicle number $(66 \%)$ and panicle mass $(66 \%)$ was more pronounced in cv. Kamini compared to other cultivars. In addition, fertile spikelet [\%] was significantly higher in cv. Varshadhan compared to other cultivars under SF. The harvest index was significantly higher in cv. Gayatri under control conditions. The harvest index remarkably declined under SF and greater reduction was observed in cv. Kamini.

Effect of stagnant flooding on minimal $\left(F_{0}\right)$ and maximal fluorescence $\left(\mathbf{F}_{\mathbf{m}}\right)$ : Table 2 depicts the values of $F_{0}$ and $\mathrm{F}_{\mathrm{m}}$ at different days of stagnant flooding. Comparison of mean values of $\mathrm{F}_{0}$ between control and $\mathrm{SF}$ revealed that the values of $\mathrm{F}_{0}$ were significantly higher under $\mathrm{SF}$ at $15 \mathrm{~d}$ of observation, whereas, the values significantly decreased from $30 \mathrm{~d}$ to flowering time due to SF (Table 2). Though on an average the value of $F_{0}$ at FLT was high under control compared to $\mathrm{SF}$, the value of $\mathrm{F}_{0}$ was significantly higher under SF in Kamini at FLT. In cvs. Savitri-Sub1 and Gayatri, on the other hand, the values significantly decreased under SF at FLT. In other cultivars the differences were insignificant. The $\mathrm{F}_{\mathrm{m}}$ changed significantly under SF compared with control at 15 and $30 \mathrm{~d}$ of SF (Table 2). The values of $F_{m}$ started to decline under SF from $45 \mathrm{~d}$ to FLT. The differences between control and SF treatment at FLT were, however, nonsignificant. The differences between control and SF were nonsignificant at FLT in most of the cases, except in cv. Gayatri.

O-J-I-P transient analysis: O-J-I-P transients and associated parameters of three cvs., such as Kamini, Rashpanjor, and Varshadhan, are presented here. The cultivars were chosen based on their performances under stagnant flooding. The Kamini cv. was the poor yielder, whereas cv. Rashpanjor was the best yielding type under stagnant flooding. The yielding ability of the cv. Varshadhan was intermediate for the same situation. Analysis of the O-J-I-P transients showed that the prominent effects of SF stress on rice plants occurred in the $\mathrm{O}-\mathrm{J}$ and $\mathrm{J}-\mathrm{I}$ phase (Fig. $2)$. The shapes of O-J-I-P transients are almost similar in all the studied cultivars under control, and under SF even 


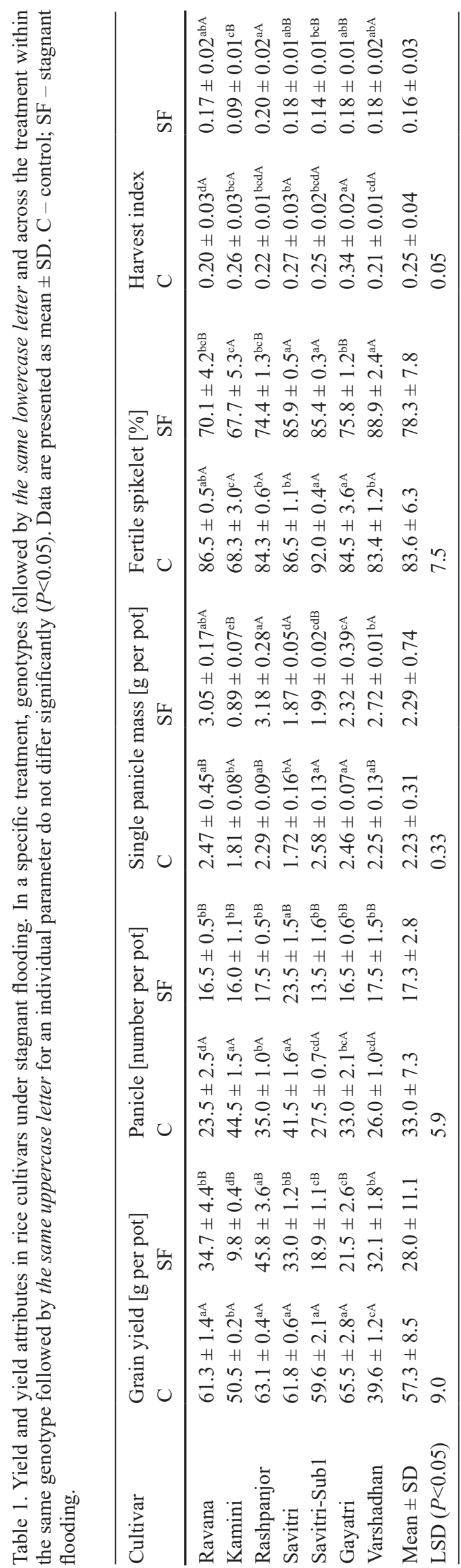

up to FLT stage in all the three cultivars with little change. In cv. Kamini, suppression of P-step was comparatively greater after 30 and $45 \mathrm{~d}$ of SF compared with control.

In order to understand better the effects of SF on photochemical activity, early fluorescence rise pattern of the O-J-I-P curves were studied (Fig. 3). Clear-cut L-band $\left(\Delta \mathrm{W}_{\mathrm{OK}}\right)$ appeared at FLT under SF compared with control in all the three represented cvs., Kamini, Rashpanjor, and Varshadhan (Fig. 3). Fluorescence rise between $F_{100 \mu s}$ and $\mathrm{F}_{150 \mu \mathrm{s}}$ was greater in cv. Rashpanjor, followed by cvs. Kamini and Varshadhan. L-band was absent after 15, 30,45 , and $60 \mathrm{~d}$ of SF in cv. Rashpanjor, whereas some fluorescence rise was noticed after 30 and $45 \mathrm{~d}$ of SF in other two cultivars. However, the fluorescence rise was far below after 30 and $45 \mathrm{~d}$ compared to FLT under SF. Like L-band, definite $\mathrm{K}$-band $\left(\Delta \mathrm{W}_{\mathrm{OJ}}\right)$ appeared at FLT under $\mathrm{SF}$ in all the three cultivars. The rise of K-band at $\mathrm{F}_{300 \mu \mathrm{s}}$ was greater in cv. Kamini. The rise of K-band was not so different between cv. Rashpanjor and cv. Varshadhan at FLT under SF. Fluorescence rise under SF occurred at $\mathrm{F}_{300 \mu \mathrm{s}}$ (K-band) in Kamini after 30 and $60 \mathrm{~d}$, in cv. Rashpanjor after $45 \mathrm{~d}$, and in cv. Varshadhan after 45 and $60 \mathrm{~d}$ of SF.

Stagnant flooding greatly altered the both electron acceptor and donor side of PSII (Fig. 4). Two parameters, i.e., $\mathrm{V}_{\mathrm{K}}$ and $\Phi_{\mathrm{P} 0}$ were employed to characterize the photosynthetic performance at the donor side of PSII. Of the two parameters the maximum quantum yield of primary photochemistry $\left(\Phi_{\mathrm{P} 0}\right)$ was less affected at different days of SF, whereas relative variable fluorescence at the K-step $\left(V_{K}\right)$ was significantly changed after $60 \mathrm{~d}$ and at FLT under SF in all the cultivars. The increase of the values of $V_{K}$ was greater in cv. Kamini, followed by cultivars Varshadhan and Rashpanjor. The acceptor site of PSI parameters, such as $\Psi_{\mathrm{R} 0}$ (efficiency or probability with which a PSII trapped electron is transferred to final electron acceptors of PSI) and $\Phi_{\mathrm{E} 0}$ (quantum yield of reduction in the end electron acceptors of PSI on absorption basis) were higher after 30 and $45 \mathrm{~d}$ of SF in all the cultivars. However, the magnitude of increase was far lesser in cv. Kamini compared to other two cultivars. The values of these two parameters decreased greatly at FLT under SF especially in cv. Kamini compared to other cultivars.

With respect to the overall photosynthetic performance index, $\mathrm{PI}_{\mathrm{ABS}}$ and $\mathrm{PI}_{\mathrm{TOT}}$, which are used to assess photosynthetic performance of PSII based on light absorption efficiency and capability to reduce the PSI end acceptor, respectively, were found differentially changed during different growth stages under SF (Fig. 5). Significant increase of $\mathrm{PI}_{\mathrm{ABS}}$ was observed during 30 and $45 \mathrm{~d}$ under SF except in cv. Kamini, where significant increase was noticed during $30 \mathrm{~d}$ of $\mathrm{SF}$. $\mathrm{PI}_{\mathrm{ABS}}$ significantly declined compared with control at FLT stage under SF only in cv. Kamini. No such significant reduction was observed in other two cultivars. $\mathrm{PI}_{\text {Tот }}$ on the other hand significantly declined in all the cultivars at FLT under SF compared with the control. However, the reduction was greater in cv. Kamini compared to cv. Rashpanjor and cv. Varshadhan. The significant decline of $\mathrm{PI}_{\mathrm{TOT}}$ was also noticed after $60 \mathrm{~d}$ of SF in cvs. Kamini and Rashpanjor. 


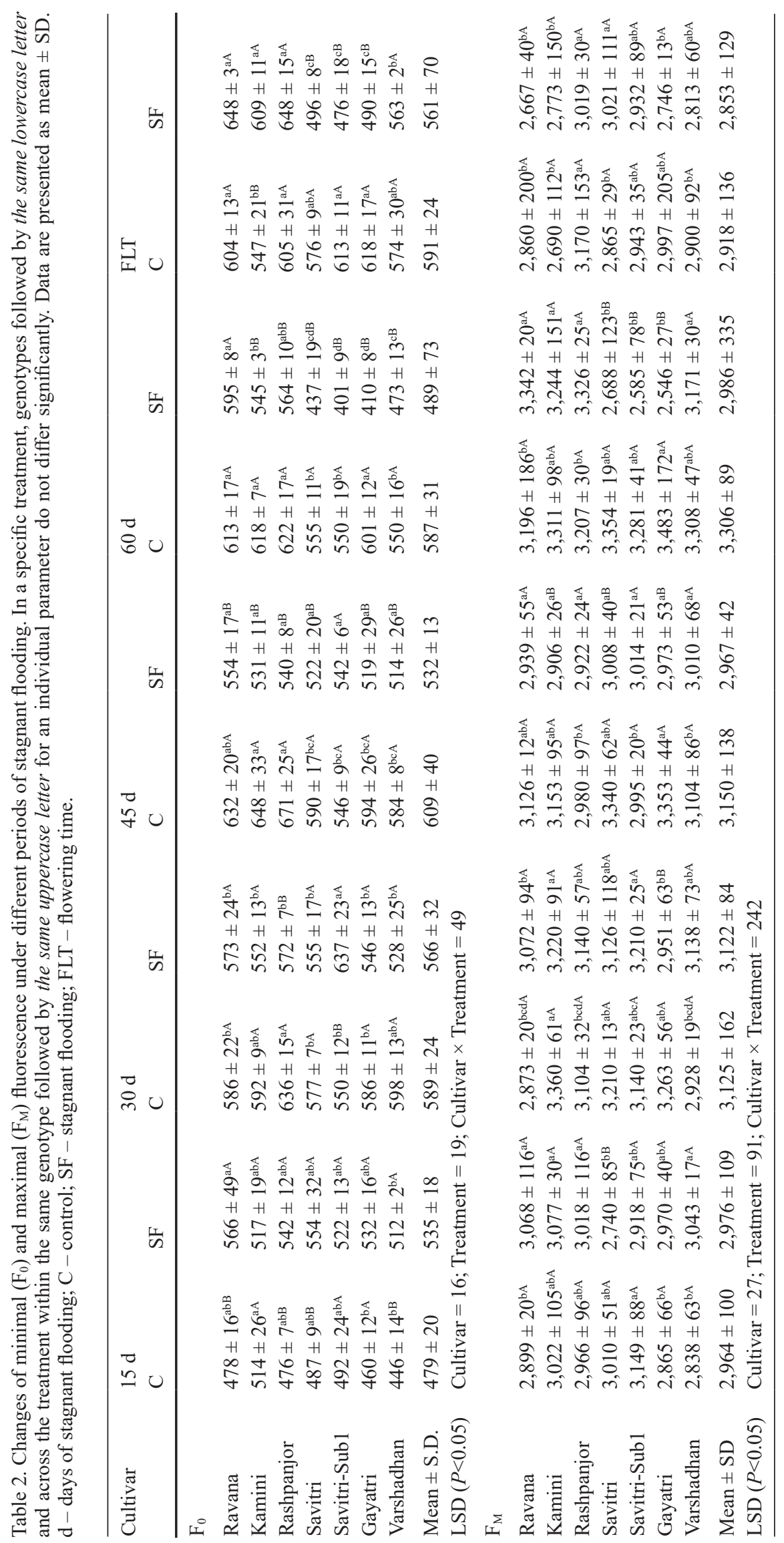




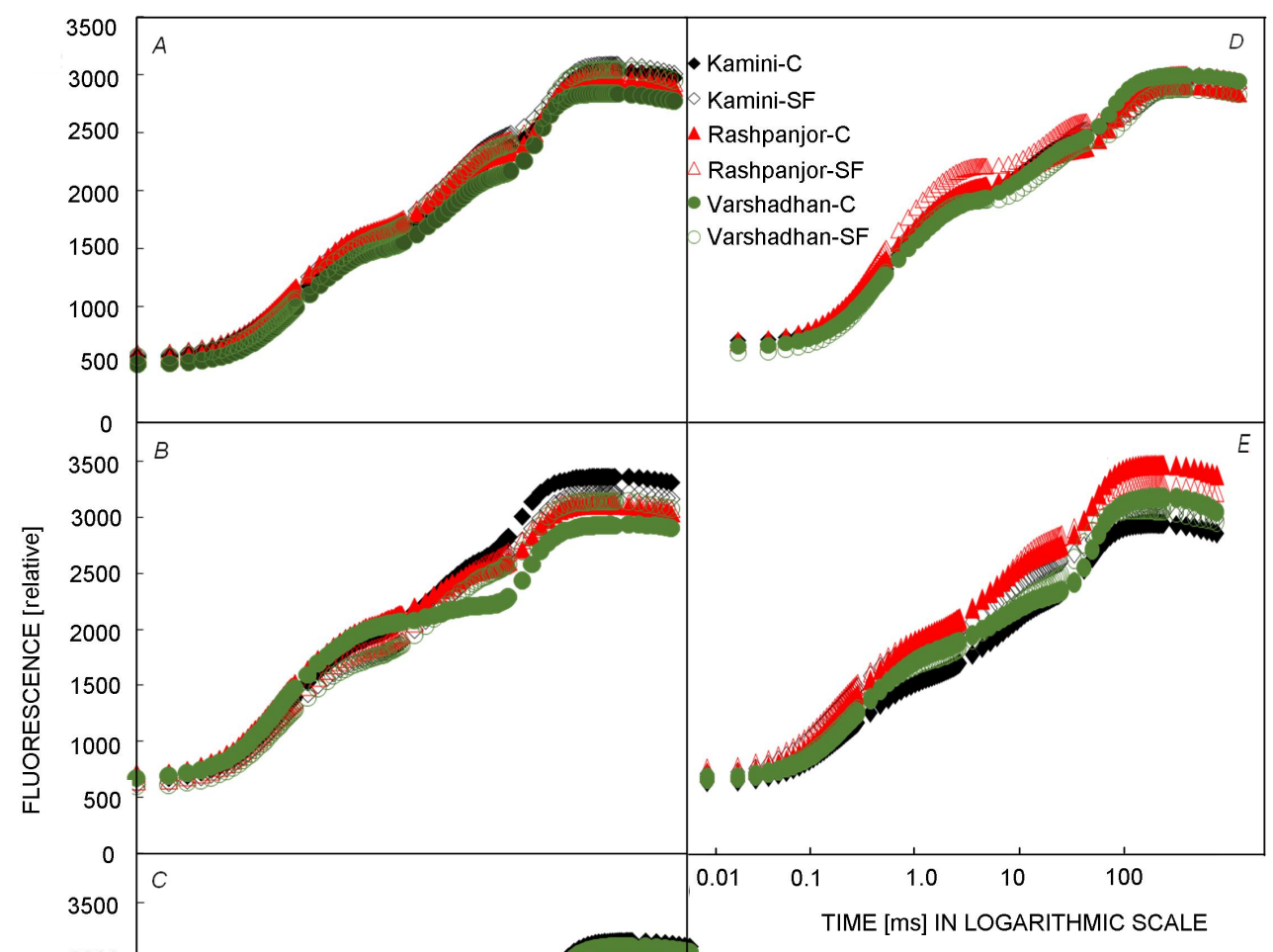

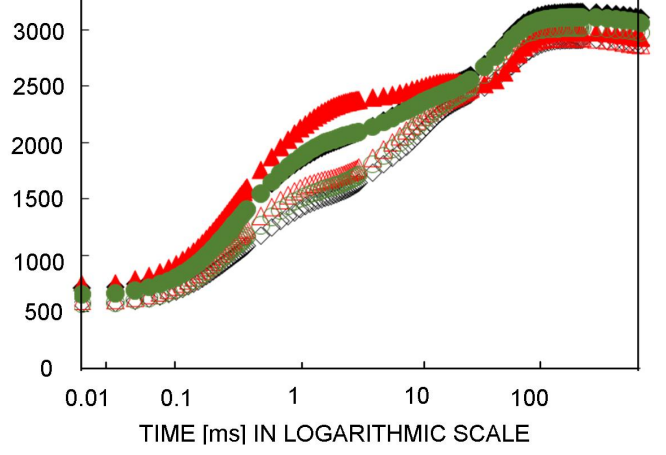

Relationship of grain yield attributes with $\mathrm{Chl} a$ fluorescence parameters under control and SF treatments were studied by simple correlation analysis (Table 3 ). A strong positive correlation between the grain yield with photosynthetic performance index $\left(\mathrm{PI}_{\mathrm{TOT}}\right.$ and $\left.\mathrm{PI}_{\mathrm{ABS}}\right)$ and efficiency of electron transports of PSII $\left(\Phi_{\mathrm{P} 0}, \Phi_{\mathrm{R} 0}\right.$, and $\left.\Phi_{\mathrm{E} 0}\right)$ was observed. Yield was negatively correlated with $\mathrm{V}_{\mathrm{K}}$ (Table 3). Similarly, panicle number and harvest index were also positively correlated with performance index and efficiency of transport of electron of PSII.

\section{Discussion}

Stagnant flooding significantly increased the stem elongation in all the studied cultivars except Sabitri-Sub1 (Fig. 1). Under SF, a greater portion of plant parts remains under water for a long time. Rice plant, in general, tries to expose more shoot part into air and avoids SF stress (Striker 2012, Vergara et al. 2014, Kuanar et al. 2017). The megashort-statured rice cultivar with SUB1 (e.g., Sabitri-Sub1) did not perform well under SF. This result confirms that semidwarf SUB1 cultivar may not be suitable for SF
Fig. 2. Changes in the chlorophyll fluorescence transient in different rice cultivars under control $(C)$ conditions and $15 \mathrm{~d}(A)$, $30 \mathrm{~d}(B), 45 \mathrm{~d}(C), 60 \mathrm{~d}(D)$, and $75 \mathrm{~d}(E)$ of stagnant flooding (SF).

(Kuanar et al. 2017). Stagnant flooding significantly decreased yield and changed yield-attributing parameters (Table 1). Reduction of grain yield under SF was reported earlier (Singh et al. 2011, Vergara et al. 2014, Kuanar et al. 2017). Rice yield, a complex trait, is influenced by several biotic and abiotic factors due to the changes in growth and developmental pattern. In the present study, some cultivars, such as Rashpanjor, Savitri, and Ravana, produced higher yield under SF compared to the rest of the cultivars. Yield-attributing parameters, such as panicle numbers per unit area and harvest index, were also higher in these three cultivars under SF. It suggested that these rice cultivars were more resilient to medium depth SF.

The value of $F_{0}$ increased at the early stage of stagnant flooding ( $15 \mathrm{~d}$ of SF) compared with control in all the rice cultivars. Increase of $\mathrm{F}_{0}$ is very common due the influence of any external factors (Kalaji et al. 2018) whereas decrease of $\mathrm{F}_{0}$ mainly happens under submergence (Panda et al. 2006). With progression of SF, rice started to acclimatise to the environment and all the cultivars maintained comparable $\mathrm{F}_{0}$ value with that of control except a few rice cultivars (Table 2). Rice is a water-loving plant, 


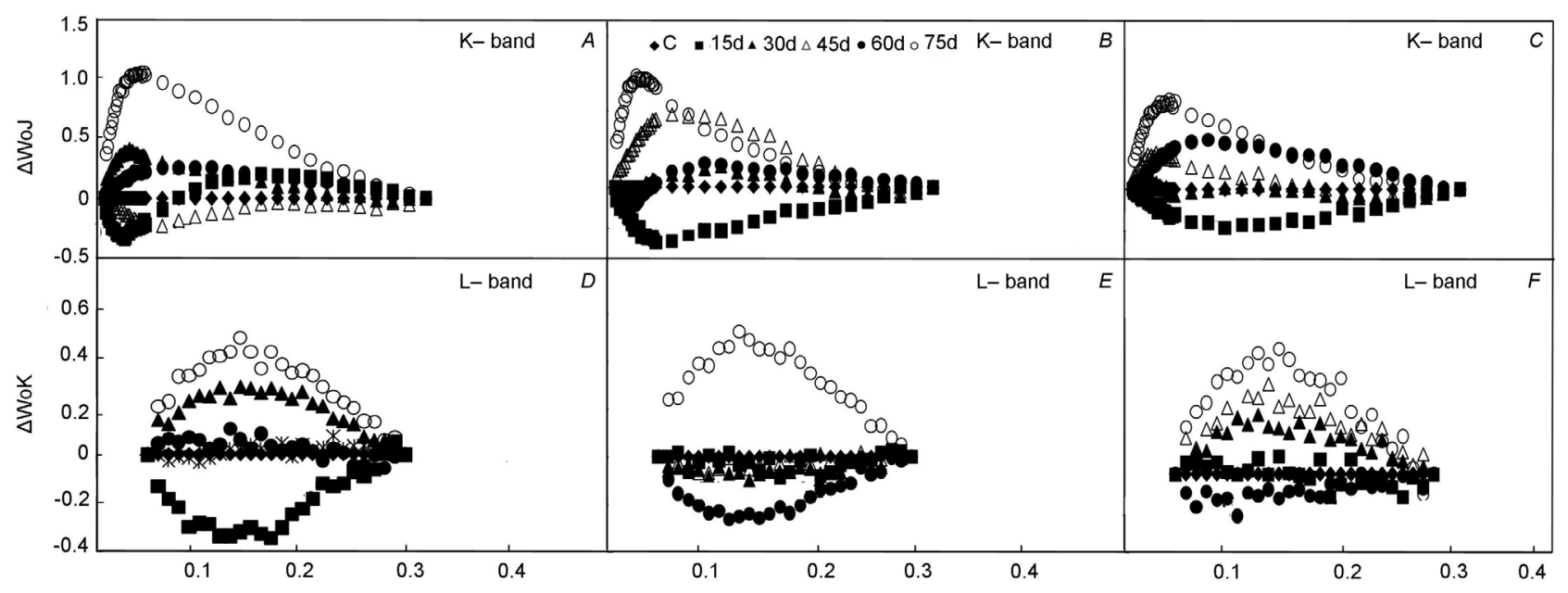

Fig. 3. Responses of the L- and K- band of rice cultivars Kamini $(A, D)$, Rashpanjor $(B, E)$, and Varshadhan $(C, F)$ under control $(C)$ conditions and 15, 30, 45, 60, and $75 \mathrm{~d}$ of stagnant flooding (SF). The fluorescence rise kinetics normalized by $\mathrm{F}_{0}$ and $\mathrm{F}_{\mathrm{K}}$ were expressed as the difference kinetics $\Delta \mathrm{W}_{\mathrm{OK}}=\mathrm{W}_{\mathrm{OK}}$ (treatment) $-\mathrm{W}_{\mathrm{OK}}$ (control). The fluorescence rise kinetics normalized by $\mathrm{F}_{0}$ and $\mathrm{F}_{\mathrm{J}}$ were expressed as the difference kinetics $\Delta \mathrm{W}_{\mathrm{OJ}}=\mathrm{W}_{\mathrm{OJ}}$ (treatment) $-\mathrm{W}_{\mathrm{OJ}}$ (control).

so acclimatization of rice to water stagnation is possible. Unlike $\mathrm{F}_{0}$, the changes in $\mathrm{F}_{\mathrm{m}}$ were comparatively mild and in most of the cases the changes were nonsignificant. Increase of $\mathrm{F}_{0}$ with concomitant decrease or restricting the increase of $\mathrm{F}_{\mathrm{m}}$ is the sign of injury to plant (Hazrati et al. 2016). In cv. Kamini, the value of $F_{0}$ was greater at FLT under $\mathrm{SF}$, yet the value of $\mathrm{F}_{\mathrm{m}}$ did not increase significantly compared with control. It showed that prolonged SF had some bad consequences on certain rice cultivars, yet it was not possible to make distinction between tolerant and susceptible cultivars purely viewing the values of $F_{0}$ and $F_{m}$ (Table 2). Absolute values of $F_{0}$ and $F_{m}$ are not so sensitive parameters to distinguish a tolerance level (Panda et al. 2006).

Submergence affects leaf photosynthesis in rice, which is well documented (Panda et al. 2006, 2008); however, the photosynthetic performance under stagnant flooding is less understood so far. To clarify the alterations of PSII activity in rice under SF stress, we used $\mathrm{Chl} a$ fluorescence induction kinetics (O-J-I-P) transients analysis or JIP test. The shape of the O-J-I-P transient is very sensitive to different biotic and abiotic stresses (Xing and Wu 2014). Under SF the shape of O-J-I-P transients was almost similar in all the studied materials with varying maximal fluorescence (Fig. 2). The data revealed that unlike other abiotic stresses the effect of SF on rice is somewhat mild irrespective of the cultivars tested; all the tested materials maintained a similar pattern of O-J-I-P rise with minor variations. Under nonstress conditions, the O-J-I-P shape did not differ between the cultivars (Fig. 2). However, under certain conditions, additional steps, such as L- and $\mathrm{K}$-band, may appear in the polyphasic fluorescence rise (Lazár 2006, Lazár and Schansker 2009). The presence of L-band signifies the loss of energetic connectivity due to the decrease of grouping probability of the PSII units (Strasser and Stirbet 1998, Jiang et al. 2006). A flowering stage was found to be more vulnerable than other stages as all the cultivars lost their energetic connectivity mainly at FLT under SF (Fig. 3). In cv. Varshadhan, the extent of increase of L-band was not so high as compared to cv. Rashpanjor and cv. Kamini. Under stress conditions, K-step appears because of partial inactivation of oxygenevolving complex (OEC) and loss of connectivity among PSII (Oukarroum et al. 2014, Wang et al. 2017). The data showed that cv. Kamini was greatly affected under SF as the magnitude of K-band was higher in comparison with other two cultivars.

Electron transport in photosystems is divided into three major steps, such as trapping of photon, electron transport to $\mathrm{Q}_{\mathrm{A}}$, and from $\mathrm{Q}_{\mathrm{A}}^{-}$to intersystem electron acceptors and reduction of end acceptors of PSI (Strasser et al. 2004, Kalaji et al. 2018, Stirbet et al. 2018). To dissect the impact of SF stress on electron transport chain, we estimated the values of different parameters of JIP-test associated with overall PSII function $\left(\mathrm{V}_{\mathrm{K}}\right.$ and $\left.\Phi_{\mathrm{P} 0}\right)$, PSII acceptor side $\left(\Psi_{\mathrm{E} 0}\right.$ and $\left.\Phi_{\mathrm{E} 0}\right)$, and overall functions of PSI $\left(\Psi_{\mathrm{R} 0}\right.$ and $\left.\Phi_{\mathrm{R} 0}\right)$. The data revealed that PSI acceptor side was greatly affected under SF compared to both PSII functions and acceptor sides (Fig. 4). Comparison among cultivars Kamini, Rashpanjor, and Varshadhan showed that mainly at FLT under SF, the values of $V_{K}$ were greater, whereas the values of other parameters, such as $\Psi_{\mathrm{R} 0}, \Phi_{\mathrm{E} 0}$, and $\Psi_{\mathrm{R} 0}$, were comparatively low in cv. Kamini compared to other cultivars. The increase of the value of $V_{K}$ and decrease of the values of other parameters are the sign of damage. The cv. Rashpanjor was the greater yielder under SF. On the other hand, yield stability was greater in cv. Varshadhan, whereas the yield was the least in cv. Kamini (Table 1). Under SF, as much as $80 \%$ yield reduction occurred in cv. Kamini. This finding is consisted with the earlier observation in hybrid rice under drought (Wang et al. 2017). Considerable decline of $\Phi_{\mathrm{R} 0}$ was observed under SF which indicated that the intersystem electron transport was inhibited in rice under SF. It is suggested that $\Phi_{\mathrm{P} 0}$ is a useful indicator of different stresses, however, this result showed that SF stress had insignificant effect on $\Phi_{\mathrm{P} 0}$ 


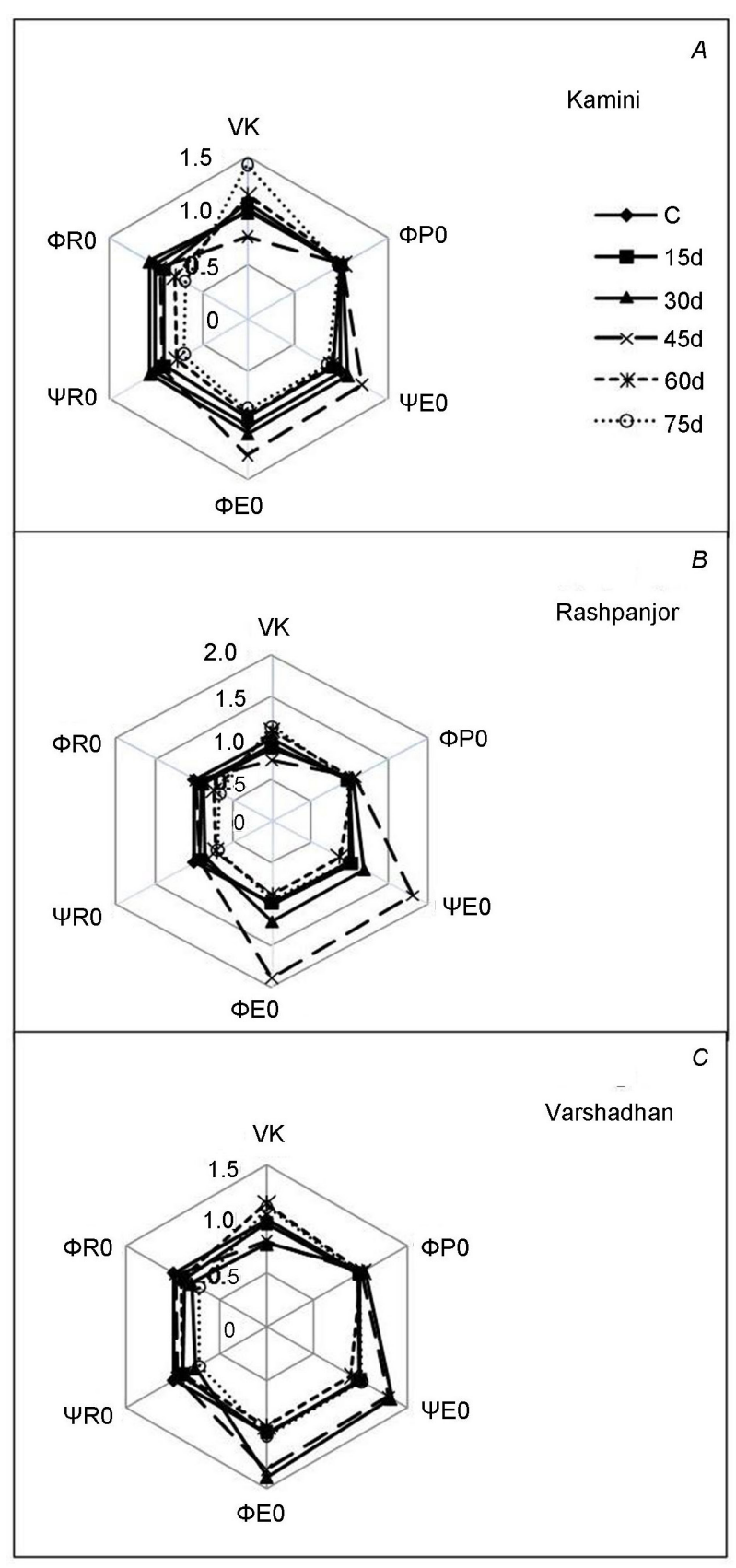

Fig. 4. Spider plots of selected fluorescence transient parameters characterizing behaviour of PSII of rice cultivars under control (C) conditions and 15, 30, 45, 60, and $75 \mathrm{~d}$ of stagnant flooding (SF). All values are normalized against control value (values under treatment/values under control). $V_{K}-$ relative variable fluorescence at the K-step (at $300 \mu \mathrm{s}$ ); $\Phi_{\mathrm{P} 0}$ - maximum quantum yield of primary PSII photochemistry that leads to $\mathrm{Q}_{\mathrm{A}}$ reduction; $\Psi_{\mathrm{E} 0}-$ efficiency or probability with which a PSII trapped electron is transferred from $\mathrm{Q}_{\mathrm{A}}^{-}$to $\mathrm{PQ}$ pool; $\Phi_{\mathrm{E} 0}-$ quantum yield of electron transport flux from $\mathrm{Q}_{\mathrm{A}}^{-}$to PQ pool of PSII on absorption basis; $\Psi_{\mathrm{R} 0}$ - efficiency or probability with which a PSII trapped electron is transferred to final electron acceptors of PSI; $\Phi_{\mathrm{R} 0}$ - quantum yield of reduction in the end electron acceptors of PSI on absorption basis.
(Živčák et al. 2014).

$\mathrm{PI}_{\mathrm{ABS}}$, a multiparametric expression of three independent steps of PSII has been frequently used as a highly sensitive stress indicator (Yusuf et al. 2010, Singh and Sarkar 2014, Stirbet et al. 2018). To compare the overall primary photochemistry or movement of electron within PSII system, $\mathrm{PI}_{\mathrm{ABS}}$ was found to be more sensitive than $\Phi_{\mathrm{P} 0}$ (Fig. 5). Overall, cultivars Rashpanjor and Varshadhan maintained greater values of $\mathrm{PI}_{\mathrm{ABS}}$ compared to cv. Kamini during the entire period of SF (Fig. 5). Total photosynthetic performance index $\left(\mathrm{PI}_{\mathrm{TOT}}\right)$ considers transport of electron beyond PSII, i.e., from $\mathrm{PQH}_{2}$ to the final PSI acceptors (Yusuf et al. 2010, Stirbet et al. 2018). The sequential energy transduction starting from absorption of light, then formation and transport of electron within PSII system, and subsequently transport of such electron to PSI end acceptors goes on in any system where light energy is used for photosynthesis. So, $\mathrm{PI}_{\mathrm{TOT}}$ is a robust parameter, which explains the potential of the transport of electron from exciton to the reduction of PSI end acceptors. As SF affects more PSI than PSII, the values of $\mathrm{PI}_{\text {TOT }}$ were always lower than that of $\mathrm{PI}_{\mathrm{ABS}}$ (Fig. 5). $\mathrm{PI}_{\mathrm{TOT}}$ significantly decreased after $60 \mathrm{~d}$ of SF in Kamini and Rashpanjor, whereas a significant decline of $\mathrm{PI}_{\text {TOT }}$ was only noticed at FLT stage in Varshadhan (Fig. 5). Rashpanjor, however, maintained greater values of $\mathrm{PI}_{\mathrm{TOT}}$ than that of Kamini. $\mathrm{PI}_{\text {TOT }}$ is the total photochemical activity in the observed system. It takes care of overall events involved in O-J-I-P fluorescence rise. The inhibition of $\mathrm{PI}_{\mathrm{TOT}}$, especially in Kamini, which gave lesser yields, suggested that this parameter was highly sensitive enough to identify best lines under SF.

Under stress-free environment, photosynthetic performances may not relate to the yield; however, under stressful conditions, preservation of photosynthetic system is vital for survival and production (Gu et al. 2014, Haritha et al. 2017). Strong correlation between grain yield with photosynthetic performance index $\left(\mathrm{PI}_{\mathrm{ABS}}\right.$ and $\left.\mathrm{PI}_{\mathrm{TOT}}\right)$ and efficiency of electron transport of PSII ( $\Phi_{\mathrm{R} 0}$ and $\left.\Phi_{\mathrm{E} 0}\right)$ was observed (Table 3). These Chl fluorescence parameters were closely associated with healthiness of photosynthetic systems under SF and were able to predict the greater yielding ability under the stress. Zhang et al. (2015) reported that super-high-yielding hybrid rice maintained greater activity of PSII compared to low-yielding traditional hybrid rice. Present study suggested that screening of rice cultivars with higher yield under SF based on leaf PSII activity may be a useful strategy.

Conclusion: Stagnant flooding imparted stem elongation. Yielding ability of rice decreased under mediumdepth water stagnation. Semidwarf rice cultivar with Submergence (SUBI) gene was not suitable under SF. Under stagnant flooding, the shape of chlorophyll $a$ fluorescence O-J-I-P transients did not change much even after prolonged period (> 2 months) of SF. However, overall functions of PSII and PSI photochemistry were perturbed under SF. With progression of duration of SF, primary photochemistry, starting from trapping of energy, intersystem electron transport (within PSII), and electron 


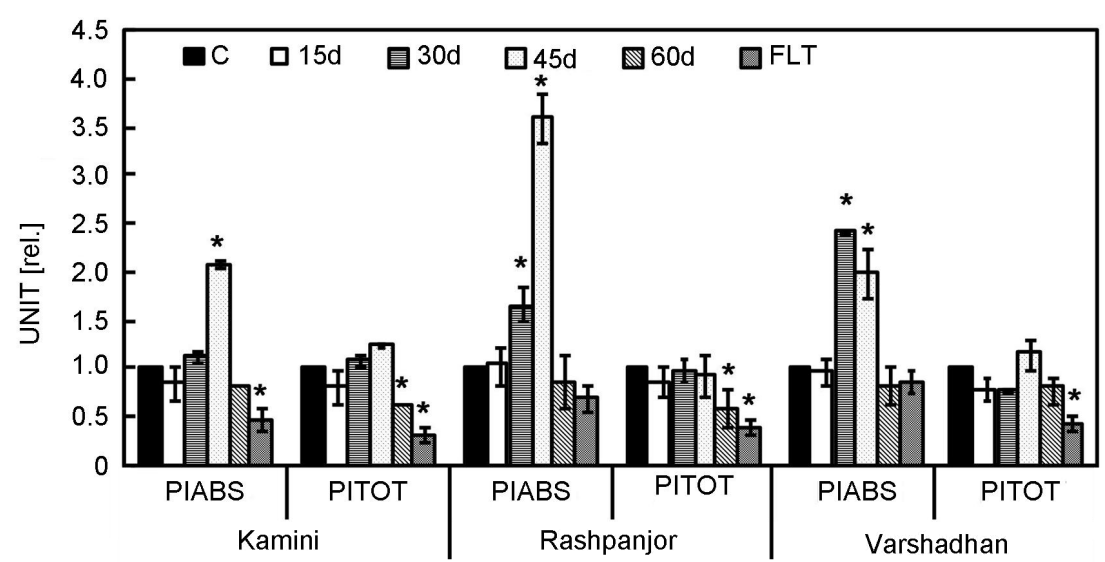

Fig. 5. Changes in performance index $\left(\mathrm{PI}_{\mathrm{ABS}}\right.$ and $\mathrm{PI}_{\text {Tот }}$ ) in rice cultivars under control (C) conditions and 15, 30, 45, and $60 \mathrm{~d}$ of stagnant flooding (SF) and in flowering time (FLT). Data are the means $\pm \mathrm{SD}, n=3$. * - significance at $P<0.05$, ns - nonsignificant. $\mathrm{PI}_{\mathrm{ABS}}$ - performance index on absorption basis; $\mathrm{PI}_{\mathrm{TOT}}$ - total performance index on absorption basis.

Table 3. Correlation coefficient ( $r$ value) between grain yield and yield attributes with leaf chlorophyll fluorescence parameters in rice seedlings grown in control and stagnant flooding conditions. The data of different JIP-test parameters during flowering stage were used. Total degrees of freedom $=18 ;{ }^{*}$ - significance at $P<0.05,{ }^{* *}$ - significance at $P<0.01$, ns - nonsignificant; $\mathrm{V}_{\mathrm{K}}-$ relative variable fluorescence at the K-step (at $300 \mu \mathrm{s}$ ); $\Phi_{\mathrm{P} 0}$ - maximum quantum yield of primary PSII photochemistry that leads to $\mathrm{Q}_{\mathrm{A}}$ reduction; $\Psi_{\mathrm{E} 0}$ - efficiency or probability with which a PSII trapped electron is transferred from $\mathrm{Q}_{\mathrm{A}}^{-}$to PQ pool; $\Phi_{\mathrm{E} 0}-$ quantum yield of electron transport flux from $\mathrm{Q}_{\mathrm{A}}^{-}$to PQ pool of PSII on absorption basis; $\Psi_{\mathrm{R} 0}$ - efficiency or probability with which a PSII trapped electron is transferred to final electron acceptors of PSI; $\Phi_{\mathrm{R} 0}$ - quantum yield of reduction in the end electron acceptors of PSI on absorption basis; $\mathrm{PI}_{\mathrm{ABS}}$ - performance index on absorption basis; $\mathrm{PI}_{\mathrm{TOT}}$ - total performance index on absorption basis.

\begin{tabular}{lllllrlll}
\hline Parameter & $\mathrm{V}_{\mathrm{K}}$ & $\Phi_{\mathrm{P} 0}$ & $\Psi_{\mathrm{E} 0}$ & $\Phi_{\mathrm{E} 0}$ & $\Psi_{\mathrm{R} 0}$ & \multicolumn{1}{c}{$\Phi_{\mathrm{R} 0}$} & $\mathrm{PI}_{\mathrm{ABS}}$ & $\mathrm{PI}_{\mathrm{TOT}}$ \\
\hline Grain yield & $-0.653^{*}$ & $0.702^{* *}$ & $0.545^{*}$ & $0.631^{* *}$ & $-0.211^{\text {ns }}$ & $0.414^{* *}$ & $0.644^{* *}$ & $0.375^{*}$ \\
Panicle number & $-0.706^{* *}$ & $0.553^{*}$ & $0.727^{* *}$ & $0.755^{* *}$ & $0.557^{*}$ & $0.525^{*}$ & $0.752^{* *}$ & $0.461^{*}$ \\
Panicle mass & $-0.312^{\text {ns }}$ & $0.311^{\text {ns }}$ & $0.265^{\text {ns }}$ & $0.297^{\text {ns }}$ & $-0.784^{* *}$ & $0.077^{\text {ns }}$ & $0.229^{\text {ns }}$ & $0.089^{\text {ns }}$ \\
Harvest index & $-0.863^{* *}$ & $0.645^{* *}$ & $0.848^{* *}$ & $0.878^{* *}$ & $0.050^{\text {ns }}$ & $0.578^{*}$ & $0.843^{* *}$ & $0.543^{*}$ \\
\hline
\end{tabular}

transport beyond PSII up to acceptor side of PSI, was inhibited greatly in the cv. Kamini, which failed to produce enough yield under SF. Rashpanjor, a cultivar with high yield potential under SF maintained better functionality of PSII compared to other cultivars. Prolonged stagnant flooding was more injurious to the acceptor side of PSI than to acceptor side of PSII. The results also suggest that the analysis of the fast O-J-I-P fluorescence transient provides good clue to predict stabilization of rice yield under SF.

\section{References}

Bailey-Serres J., Colmer T.D.: Plant tolerance of flooding stress recent advances. - Plant Cell Environ. 37: 2211-2215, 2014.

Bailey-Serres J., Voesenek L.A.C.J.: Flooding stress: acclimations and genetic diversity. - Annu. Rev. Plant Biol. 59: 313-339, 2008.

Batra N.G., Kumari N., Sharma V.: Photosynthetic performance of Ocimum sanctum morphotypes in a semiarid region. J. Herb. Spice. Med. Plant. 22: 211-224, 2016.

Bin Rahman A.N.M.R., Zhang J.: Flood and drought tolerance in rice: Opposite but may coexist. - Food Energ. Secur. 5: 76-88, 2016.

Cattling D.: Rice in Deep Water. Pp. 542. The Macmillan Press, London 1992.

Dar M.H., de Janvry A., Emerick K. et al.: Flood-tolerant rice reduces yield variability and raises expected yield, differentially benefitting socially disadvantaged groups. - Sci.
Rep.-UK 3: 3315, 2013.

Goswami S., Kar R.K., Paul A., Dey N.: Genetic potentiality of indigenous rice genotypes from Eastern India with reference to submergence tolerance and deepwater traits. - Curr. Plant Biol. 11-12: 23-32, 2017.

Gu J.F., Yin X.Y., Stomph T.J., Struik P.C.: Can exploiting natural genetic variation in leaf photosynthesis contribute to increasing rice productivity? A simulation analysis. - Plant Cell Environ. 37: 22-34, 2014.

Haritha G., Vishnukiran T., Yugandhar P. et al.: Introgressions from Oryza rufipogon increase photosynthetic efficiency of KMR3 rice lines. - Rice Sci. 24: 85-96, 2017.

Hattori Y., Nagai K., Furukawa S. et al.: The ethylene response factors SNORKEL1 and SNORKEL2 allow rice to adapt to deep water. - Nature 460: 1026-1030, 2009.

Hazrati S., Tahmasebi-Sarvestani Z., Modarres-Sanavy S.A.M. et al.: Effects of water stress and light intensity on chlorophyll fluorescence parameters and pigments of Aloe vera L. - Plant Physiol. Bioch. 106: 141-148, 2016.

Jiang C.D., Shi L., Gao H.Y. et al.: Development of photosystem 2 and 1 during leaf growth in grapevine seedlings probed by chlorophyll $a$ fluorescence transient and $820 \mathrm{~nm}$ transmission in vivo. - Photosynthetica 44: 454-463, 2006.

Kalaji H.M., Rastogi A., Živčák M. et al.: Prompt chlorophyll fluorescence as a tool for crop phenotyping: An example of barley landraces exposed to various abiotic stress factors. Photosynthetica 56: 953-961, 2018.

Kuanar S.R., Ray A., Sethi S.K. et al.: Physiological basis of stagnant flooding tolerance in rice. - Rice Sci. 24: 73-84, 2017. 
Lazár D.: The polyphasic chlorophyll $a$ fluorescence rise measured under high intensity of exciting light. - Funct. Plant Biol. 33: 9-30, 2006.

Lazár D., Schansker G.: Models of chlorophyll $a$ fluorescence transients. - In: Laisk A., Nedbal L., Govindjee (ed.): Photosynthesis in Silico: Understanding Complexity From Molecules to Ecosystems. Vol. 29. Pp. 85-123. Springer, Dordrecht 2009.

Oukarroum A., Bussotti F., Goltsev V., Kalaji H.M.: Correlation between reactive oxygen species production and photochemistry of photosyntem I and II in Lemna gibba L. plants under salt stress. - Environ. Exp. Bot. 109: 80-88, 2014.

Oukarroum A., Madidi S.E., Schansker G., Strasser R.J.: Probing the responses of barley cultivars (Hordeum vulgare L.) by chlorophyll $a$ fluorescence OLKJIP under drought stress and re-watering. - Environ. Exp. Bot. 60: 438-446, 2007.

Panda D., Rao D.N., Sharma S.G. et al.: Submergence effect on rice genotypes during seedling stage: Probing of submergence driven changes of photosystem 2 by chlorophyll $a$ fluorescence induction O-J-I-P transients. - Photosynthetica 44: 69-75, 2006.

Panda D., Sarkar R.K.: Natural leaf senescence: Probed by chlorophyll fluorescence, $\mathrm{CO}_{2}$ photosynthetic rate and antioxidant enzyme activities during grain filling in different rice cultivars. - Physiol. Mol. Biol. Pla. 19: 43-51, 2013.

Panda D., Sharma S.G., Sarkar R.K.: Chlorophyll fluorescence parameters, $\mathrm{CO}_{2}$ photosynthetic rate and regeneration capacity as a result of complete submergence and subsequent re-emergence in rice (Oryza sativa L.). - Aquat. Bot. 88: 127133, 2008.

Ray A., Panda D., Sarkar R.K.: Can rice cultivar with submergence tolerant quantitative trait locus (SUB1) manage submergence stress better during reproductive stage? - Arch. Agron. Soil Sci. 63: 998-1008, 2017.

Sakagami J.I., Kawano N.: Survival of submerged rice in a floodprone region of West Africa. - Tropics 20: 55-66, 2011.

Sarkar R.K., Panda D., Reddy J.N. et al.: Performance of submergence tolerant rice (Oryza sativa) genotypes carrying the $S u b 1$ quantitative trait locus under stressed and nonstressed natural field conditions. - Indian J. Agr. Sci. 79: 876$883,2009$.

Sarkar R.K., Ray A.: Submergence-tolerant rice withstands complete submergence even in saline water: Probing through chlorophyll $a$ fluorescence induction O-J-I-P transients. Photosynthetica 54: 275-287, 2016.

Sarkar R.K., Reddy J.N., Sharma S.G., Ismail A.M.: Physiological basis of submergence tolerance in rice and implications for crop improvement. - Curr. Sci. India 91: 899-906, 2006.

Singh A., Carandang J., Gonzaga Z.J.C. et al.: Identification of QTLs for yield and agronomic traits in rice under stagnant flooding conditions. - Rice 10: 15, 2017.

Singh D.P., Sarkar R.K.: Distinction and characterization of salinity tolerant and sensitive rice cultivars as probed by the chlorophyll fluorescence characteristics and growth parameters. - Funct. Plant Biol. 41: 727-736, 2014.

Singh S., Mackill D.J., Ismail A.M.: Tolerance of longer-term partial stagnant flooding is independent of the SUB1 locus in rice. - Field Crop. Res. 121: 311-323, 2011.

Stirbet A., Lazár D., Kromdijk J., Govindjee: Chlorophyll $a$ fluorescence induction: Can just a one second measurement be used to quantify abiotic stress responses? - Photosynthetica 56: 86-104, 2018.

Strasser R.J., Stirbet A.D.: Heterogeneity of Photosystem II probed by the numerically simulated chlorophyll $a$ fluorescence rise (O-J-I-P). - Math. Comput. Simulat. 48: 3-9, 1998.

Strasser R.J., Tsimilli-Michael M., Srivastava A.: Analysis of the chlorophyll $a$ fluorescence transient. - In: Papageorgiou G.C., Govindjee (ed.): Chlorophyll $a$ Fluorescence: A Signature of Photosynthesis. Advances in Photosynthesis and Respiration. Pp. 321-362. Springer, Dordrecht 2004.

Striker G.G.: Flooding stress on plants: Anatomical, morphological and physiological responses. - In: Mworia J.K. (ed.): Botany. IntechOpen, 2012. Available at: https://www. intechopen.com/books/botany

Vergara G.V., Nugraha Y., Esguerra M.Q. et al.: Variation in tolerance of rice to long-term stagnant flooding that submerges most of the shoot will aid in breeding tolerant cultivars. - AoB Plants 6: plu055, 2014.

Wang Y., Xu C., Wu M., Chen G.: Characterization of photosynthetic performance during reproductive stage in high-yield hybrid rice LYPJ exposed to drought stress probed by chlorophyll $a$ fluorescence transient. - Plant Growth Regul. 81: 489-499, 2017.

Xing D., Wu Y.: Effect of phosphorus deficiency on photosynthetic inorganic carbon assimilation of three climber plant species. Bot. Stud. 55: 60-67, 2014.

Xu K., Xia X., Fukao T. et al.: Sub1A is an ethylene response factor-like gene that confers submergence tolerance to rice. Nature 442: 705-708, 2006.

Yusuf M.A., Kumar D., Rajwanshi R. et al.: Overexpression of $\gamma$-tocopherol methyl transferase gene in transgenic Brassica juncea plants alleviates abiotic stress: Physiological and chlorophyll a fluorescence measurements. - BBABioenergetics 1797: 1428-1438, 2010.

Zhang M., Shan Y., Kochian L. et al.: Photochemical properties in flag leaves of a super-high-yielding hybrid rice and a traditional hybrid rice (Oryza sativa L.) probed by chlorophyll $a$ fluorescence transient. - Photosynth. Res. 126: 275-284, 2015.

Živčák M., Kalaji H.M., Shao H.B. et al.: Photosynthetic proton and electron transport in wheat leaves under prolonged moderate drought stress. - J. Photoch. Photobio. B 137: 107$115,2014$.

(C) The authors. This is an open access article distributed under the terms of the Creative Commons BY-NC-ND Licence. 